УДК 811.112.2:81'373

DOI https://doi.org/10.24919/2308-4863/34-5-19

Ростислав УГРИНЮК, orcid.org/0000-0002-7789-7472 кандидат філологічних наук, дочент кафедри німеиької філології Прикарпатського національного університету імені Василя Стефаника (Івано-Франківськ, Украӥна) rostyslaw_u@ukr.net

Василь УГРИНЮК, orcid.org/0000-0032-3982-3480 кандидат філологічних наук, завідувач кафедри іноземних мов та країнознавства Прикарпатського начіонального університету імені Василя Стефаника (Івано-Франківськ, Украӥна) wassyl.ug@gтаil.com

\title{
КЛЮЧОВІ ХАРАКТЕРИСТИКИ КОНЦЕПТУ ЧИСТОТА В НІМЕЦЬКІЙ МОВНІЙ КАРТИНІ СВІТУ (НА ОСНОВІ ЯДРОВИХ КОМПОНЕНТІВ LAUTER, REIN)
}

Мовна картина світу - ие сукупність уявлень, що склалася історично в повсякденній свідомості народу $i$ відобразилася в мові. Картина світу будується на відчуттях, уявленнях, сприйнятті й мисленні людини, диктує норми поведінки, систему цінностей.

Одним із ключових фрагментів у німецькій МКС є семантичне поле чистоти, яке є відображенням відповідного фрагменту конщептуальної картини світу - конџепту SAUBERKEIT. Цей концепт є лексикалізованим $i$ належить до абстрактних концептів, оскільки включає уявлення носіїв німецької мови не лише про дотримання прийнятих у суспільстві норм, стандартів чистоти, способу поведінки, а й психічні процеси, щео відображають суб 'єктивне оцінне ставлення до існуючих або можливих ситуаиій і об 'єктивного світу.

Завданням статті було здійснити аналіз контекстних вживань компоненту lauter як прикметника, так $i$ прислівника, що об'єктивує конщепт Sauberkeit з метою виявлення його ознак, які не описуються домінантною лексемою. Апроксимативно-статистичні підрахунки застосовано з метою визначення кількісних характеристик досліджуваних мовних одиниць.

Відповідно до викладеного матеріалу ядрові компоненти lauter i rein найчастіме вербалізують такі ознаки концепту: ЧИСТОТА як емоційність, що здебільшого вказує на емоційний ступінь інтенсивності почуттів (lauter, 6460; rein, 5191), почуття моральної відповідальності (lauter, 67; rein, 2482), відповідність (lauter, 104; rein, 2435), адаптивність (rein, 2284), екологічність (rein, 3463). Мени вагомою виявилася ознака вияву властивостей характеру (позитивних / негативних) (lauter, 268). Нерелевантними ознаками є почуття моральної відповідальності (lauter, 67), ознака якості у прибиранні територій населених пунктів (rein, 39), ознака відповідності певним стандартам, нормам щодо чистоти продукту (lauter, 57), когнітивна ознака, спрямована на пізнавальні процеси людської психіки (lauter, 11), енергетична ознака, яка полягає у використанні чистих технологій у виробництві електроенергії (rein, 3).

Зіставивши результати досліджень зі словом-репрезентантою sauber та ядровими компонентом lauter i rein здебільшого ми виявили ознаки, які не описуються домінантою. Sauberkeit в уяві носї̈в німецької мови вказує на характеристики, які відображають якість життя людини, ї̈ духовне очищення та спосіб поведінки.

Ключові слова: мовна картина світу, концептуальна картина світу, семантичне поле, концепт, концептуальні ознаки. 
Rostyslav UHRYNIUK, orcid.org/0000-0002-7789-7472

Candidate of Philological Sciences, Associate Professor at the Department of German Philology Vasyl Stefanyk Precarpathian National University (Ivano-Frankivsk, Ukraine) rostyslaw_u@ukr.net

Vasyl UHRYNIUK, orcid.org/0000-0032-3982-3480 Candidate of Philological Sciences, Head of the Department of the Foreign Languages and Country Studies Vasyl Stefanyk Precarpathian National University (Ivano-Frankivsk, Ukraine)wassyl.ug@gmail.com

\section{KEY FEATURES OF THE CLEANLINESS CONCEPT IN THE GERMAN LANGUAGE PICTURE OF THE WORLD (BASED ON THE CORE COMPONENTS OF LAUTER AND REIN)}

The linguistic picture of the world is a set of ideas that has developed historically in the everyday consciousness of the people and is reflected in language. The picture of the world is based on human feelings, ideas, perception and thinking, dictates the norms of behavior, the system of values.

One of the key fragments in the German language picture of the world is the semantic field of Cleanliness, which is a reflection of the corresponding fragment of the conceptual picture of the world - the concept of SAUBERKEIT. The analyzed concept is lexicalized and belongs to the abstract concepts, because it includes the idea of native German speakers not only about compliance with social norms, standards of cleanliness, behavior, but also mental processes that reflect the subjective evaluation of existing or possible situations and objective world.

The aim of the article was to analyze the contextual uses of the lauter component as both an adjective and an adverb that objectifies the concept of Sauberkeit in order to identify its features that are not described by the dominant lexeme.

According to the presented material, the core components of lauter and rein most often verbalize such features of the concept of Cleanliness as emotionality, which indicates mainly the emotional degree of intensity of feelings (lauter, 6460; rein, 5191), moral sensitivity (lauter, 67; rein, 2482), congruence (lauter, 104; rein, 2435), adaptibility (rein, 2284), ecological compatibility (rein, 3463). Less significant were the sign of the manifestation of character traits (positive $/$ negative) (lauter, 268). Irrelevant features are a sense of moral responsibility (lauter, 67), a sign of quality in the cleaning of human settlements (rein, 39), a sign of compliance with certain standards, norms of product purity (lauter, 57), a cognitive sign aimed at cognitive processes of the human psyche (lauter, 11), energy sign, which indicates the use of clean technologies in electricity generation.

Comparing the results of research with the representative word sauber and the core components lauter and rein, we found parts of the signs that are not described by the dominant. Thus, Cleanliness in the imagination of native speakers of German mostly indicates the characteristics that reflect the quality of human life, his spiritual purification and behavior.

Key words: linguistic world-image, conceptual world view, semantic field, concept, conceptual characteristics.

Постановка проблеми. Мовна картина світу - це сукупність уявлень, що склалася історично в повсякденній свідомості народу і відобразилася у мові (Левицький, 2006). Картина світу будується на відчуттях, уявленнях, сприйнятті й мисленні людини, диктує норми поведінки, систему цінностей. Одним із ключових фрагментів у німецькій МКС є семантичне поле чистоти, яке $\epsilon$ відображенням відповідного фрагмента концептуальної картини світу - концепту SAUBERKEIT (Приходько, 2013: 112).

Вказаний концепт $є$ лексикалізованим і належить до абстрактних концептів, оскільки включає в себе уявлення носіїв німецької мови не лише про дотримання прийнятих у суспільстві норм, стандартів чистоти, способу поведінки, а й психічні процеси, які відображають суб'єктивне оцінне ставлення до існуючих або можливих ситуацій і об'єктивного світу.

Аналіз досліджень. Вивчення концепту ЧИСТОТА сучасної німецької мови уже було предметом дослідження, проте здебільшого це були зіставні дослідження (німецька чистота на противагу англійській) (Дронова, 2013) або ж його побічний опис в рамках дослідження концепту GRÜNDLICHKEIT (Мєдвєдєва, 2015).

Завданням статті було здійснити аналіз контекстів із компонентами lauter i rein як прикметника, так і прислівника, що об'єктивує концепт Sauberkeit 3 метою виявлення його ознак, які не описуються домінантною лексемою.

Методи дослідження зумовлені реалізацією мети і завдань дослідження. Метод корпусного аналізу (Остапович, 2008) використаний для 
добору мовного матеріалу із Мангеймського корпусу німецької мови (COSMAS). Апроксимативно-статистичні підрахунки застосовано 3 метою визначення кількісно-частотних характеристик досліджуваних мовних одиниць.

Виклад основного матеріалу. Під час аналізу мовного матеріалу визначено комплекс концептуальних ознак (далі - КО) з метою максимально повного охоплення змісту досліджуваного концепту. Відповідно до викладеного матеріалу найчастотнішими ознаками концепту SAUBERKEIT за компонентом lauter $€$ :

- Емоційна ознака (а), що здебільшого вказує на емоційний ступінь інтенсивності почуттів радості (Liebe, 841), напр., Alles so schön bunt hier. Laut und voller Liebe. Berlin im Liebesrausch: Die Straßen dicht. Kein Einkaufsstreß. Nur Wochenend und Sonnenschein und lauter lautere Liebe (Die Welt, 1999: 2).

- Ознака вияву властивостей характеру (позитивних / негативних), що вказує на взірцево чисту людину, почесного бюргера, чесного політика (lauterer Mensch - 110, lauterer Charakter - 46, lauter Hochmut - 47, lauteres Wesen - 27), напр., Er betrieb seit 21 Jahren mit seinem Bruder ein schwungvolles Baugeschäft und hat nicht minder zur Vergrößerung und Verschönerung unserer Stadt beigetragen. Offenes lauteres Wesen zeichnete ihn aus; Bürgermeister, Stadtdirektor und der Rat ernannten ihn auch deshalb zum Ehrenbürger, weil sie seine "unermüdliche Schaffenskraft", sein "lauteres Wesen" sowie seinen Gerechtigkeitssinn und seine Einsatzfreude für die ihm anvertrauten Bürger zu schätzen wussten; позитивна характеристика політика, напр., Einige derer, die seiner Strebsamkeit zum Opfer fielen, loben noch immer sein lauteres Wesen. Norbert Röttgen gehörte von Jugend an zu denen, die der CDU den Muff austreiben wollten (Fränkischer Tag, 2013: 17); Kommerzienrat Schaal gewährt guten Verdienst); "Ein gerader, lauterer Mensch" ... Pfarrer Alkuin Mahr würdigte den Verstorbenen als vorbildliche, soziale Persönlichkeit (FRT09/ JUN.17788 Fränkischer Tag, 2009: 15); „Ein gerader, lauterer Mensch"); Er ist ein lauterer Charakter, sehr geradlinig strukturiert, dem ich nichts Schlechtes zutraue (HAB18/APR.00786 Handelsblatt, 2018: 48; „Das macht mich unfassbar zornig"); вияв способу поведінки (21), напр., Und der Dichter Johann Gottfried Herder (1744 bis 1803) führt das Sprichwort in seinen „Zerstreuten Blättern" 1792 ins Deutsche ein: ,Lerne schweigen, o Freund. Dem Silber gleichet die Rede, aber zu rechter Zeit Schweigen ist lauteres Gold". So wertvoll wie Gold soll das Schweigen sein (Kölner Stadt-Anzeiger, 2009).
- Ознака почуття моральної відповідальності (Gewissen, 67), напр., Für den obligaten Ungehorsam kassierte er am 18 Juni 14 Tage Arrest. Die Prüfungskammer bescheinigte ihm am 5. August ein lauteres Gewissen (Der Spiegel, 1999: 50; Verstopfte Gewehre).

- Ознака відповідності (а), спрямована на об'єктивну реальність, яка не залежить від спостерігача чи суб'єктивного сприйняття (lautere Wahrheit, 47). Здебільшого вона вживається в політичному контексті. Частотності вживання ця колокація набула як крилата фраза Конрада Аденауера, який на закид щодо його неправдивого висловлювання зазначив, що існує три види правди: правда, уся правда та чиста правда, напр., Konrad Adenauer soll einmal auf den Vorwurf, $z u$ lügen, drei Wahrheiten unterschieden haben: die Wahrheit, die ganze Wahrheit und die lautere Wahrheit (General-Anzeiger, 2013: 32; Subjektive Wahrheiten Leserbrief zum Bericht); Wenn nur einer aus diesem Finanzquintett die lautere Wahrheit über die geheimnisvollen Geldbewegungen sagt, dann drohen der Partei womöglich ungeahnte weitere Folgen (General-Anzeiger, 2000: 02; AFFÄRE Schäuble und die Wahrheit Von Ekkehard); Selbst falls das alles die lautere Wahrheit sein sollte nichts davon dürfte Angela Merkel verraten (BRU11/ FEB.02333 Bayerische Rundschau, 2011: 2).

- Ознака відповідності певним стандартам, нормам щодо чистоти продукту (б) (lauteres Gold, 57), напр., Daneben kniet einer der Heiligen Drei Könige und übergibt ehrfürchtig seine Gabe-lauteres Gold (Badische Zeitung, 2012: 31; Alles strömt zum Kripplein hin).

- Когнітивна ознака, спрямована на пізнавальні процеси людської психіки (чисті помисли / lautere Gesinnung, 11), напр., Die Texte sollen dem Aus- und Inland die lautere Gesinnung der Autorinnen und Autoren versichern, bezeugen aber stattdessen deren dichterische und denkerische Selbstgefälligkeit (Nürnberger Zeitung, 2014: 21; Die Dichter des Pin-Clubs).

Відповідно до викладеного матеріалу найчастотнішою ознакою концепту SAUBERKEIT за компонентом rein $\epsilon$ емоційна, що здебільшого вказує на емоційний ступінь інтенсивності почуттів радості, втіхи (reines Vergnügen, 3019, reine Freude, 2172), напр., Elternabende sind wie Prostatavorsorge - kein reines Vergnügen (Berliner Morgenpost, 2017: 2; Don't feed the Trolls); Denn die Wirtschaftsentwicklung jenseits der Bundesgrenzen gibt keineswegs Grund zur reinen Freude (Nürnberger Nachrichten, 2010: 17; Konsumlaune im Sommerhoch); Der Hüne stakt im 
Storchengang über die Bühne, erzählt wirres Zeug und zupft dazu so unvergleichlich die vier Saiten, daß Zuhören und sehen zur reinen Freude wird (Nürnberger Nachrichten, 2010: 17; Abenteuerliche Rock-Melange - Musik wider alle Erwartungen).

- Адаптивна ознака, яка вказує на попередній досвід: знання, вміння, навички (reine Vernunft, 2284), напр., Die reine Vernunft, sie zwingt zur Zusammenarbeit mit Berlin auch in der Frage, die das Duo vor zehn Tagen zu zerreißen drohte: Die kontinentale Flüchtlingskrise (Süddeutsche Zeitung, 2016: 6; Geballte Faust, gebremster Zorn).

- Ознака екологічності (reine Luft, 2205; reines Wasser, 1258), що вказує на якісні умови проживання людини, напр., Der BUND war vor Gericht gegangen, um die Stadt zu zwingen, mehr für reine Luft zu tun und hatte recht bekommen (Hamburger Morgenpost, 2015: 8; Öko-Schlappe für die Grünen); Sie genießen übrigens nicht nur den Whisky, sondern auch das reine Wasser, das aus der hoteleigenen Quelle sprudelt (Braunschweiger Zeitung, 2009; Hier erholten sich einst die Offiziere des Kaisers).

- Ознака почуття моральної відповідальності (reines Gewissen, 2482), що вказує на духовне очищення, чисту совість, напр., "Damit ich ein reines Gewissen habe, behalte ich das Geld nicht, sondern spende es für einen guten Zweck" (Sonntags Zeitung (Tages-Anzeiger), 2017: 2; Lobbys holen mehr Politiker ins Boot denn je).

- Ознака відповідності (а), спрямована на об'єктивну реальність, яка не залежить від спостерігача чи суб'єктивного сприйняття (reine Wahrheit, 1229; reine Abzocke, 628), напр., Niemand sollte davon ausgehen, in den Akten die reine Wahrheit zu finden (Berliner Zeitung, 2019: 9; Liebe Leserinnen, liebe Leser); Der Präsident des Bundes der Steuerzahler, Reiner Holznagel, sagte der Zeitung „B.Z.“, bei sprudelnden Rekordsteuereinnahmen sei ein Festhalten am Soli ,reine Abzocke der Steuerzahler durch eine große Koalition aus Union, $S P D$, Grüne und Linke" (Bayerische Rundschau, 2013: 4; Koalition streitet über Zukunft des Solidaritätszuschlags); відповідності якості, що вказує на економічну систему суспільства (168), напр., Jetzt hat sie auffallend behutsam reagiert und betont, dass die Deutschen in einer Sozialen Marktwirtschaft und nicht im reinen Kapitalismus leben (Süddeutsche Zeitung, 2005: 4; In einem Land vor unserer Zeit).

Менш вагомою виявилася ознака відповідності певним стандартам, нормам щодо чистоти про- дукту (б) (reines Gold, 351; reines Silber, 59), напр., Gewinnen Sie eine Reise in den heilenden Berg ... Bis ins 17 Jahrhundert wurde tonnenweise reines Gold in dem österreichischen Gestein zu Tage gefördert (Berliner Kurier, 2010: 15; Gewinnen Sie eine Reise in den heilenden Berg); Manchmal verwende ich für meine Gemälde auch reines Gold', sagt sie (Frankfurter Neue Presse, 2012: 6; Unter den Flügeln eines Engels); Bei altdeutschem Silber waren von 16 Anteilen nur 12 oder 13 reines Silber (Die Welt, 2011: 28; Preußens Glanz ist krisenfest).

Найменш релевантною $є$ ознака якості у прибиранні територій населених пунктів (reine Stadt, 10; reiner Ort 28; reine Straße, 1), напр., Aachen sei eine Großstadt, sagte Servos, da werde es kaum gelingen, eine klinisch reine Stadt zu schaffen, die dem Idealbild einer schönen neuen Welt entspreche (Aachener Nachrichten, 2013: 15; Verwaltung setzt auf strenge Erziehung zur Sauberkeit) та енергетична ознака, яка полягає у використанні чистих технологій у виробництві електроенергії (3), напр., Dieser Preis für die reine Elektrizität ist längst versteckt hinter einem Dschungel von Steuern und Abgaben (Süddeutsche Zeitung, 2019: 18; Alles fließt nach oben).

Висновки. Отже, найчастотнішою ознакою концепту SAUBERKEIT за ядровими компонентами lauter, rein є емоційна, що здебільшого вказує на емоційний ступінь інтенсивності почуттів, усвідомлення моральної відповідальності, ознаку відповідності, адаптивності, екологічності. Менш вагомою виявилася ознака вияву властивостей характеру (позитивних / негативних). Нерелевантними є ознака якості у прибиранні територій населених пунктів, ознака відповідності певним стандартам, нормам щодо чистоти продукту, когнітивна ознака, спрямована на пізнавальні процеси людської психіки, енергетична ознака, яка полягає у використанні чистих технологій у виробництві електроенергії.

Зіставивши результати досліджень зі словомрепрезентантою sauber (Угринюк, 2019) та ядровими компонентами lauter, rein здебільшого ми виявили ознаки, які не описуються домінантою. Sauberkeit в уяві носіїв німецької мови здебільшого вказує на характеристики, які відображають якість життя людини, iї духовне очищення та спосіб поведінки. У перспективі ще необхідно проаналізувати й інші компоненти, які описують концепт ЧИСТОТА. 


\section{СПИСОК ВИКОРИСТАНИХ ДЖЕРЕЛ}

1. Дронова Л. П. Особенности концептуализации представления о чистоте в английском и немецком языках. Вестник Томского государственного университета. 2013. Вип. 368. С. 7-10.

2. Левицкий В. В. Семасиология : монографія. Винница : Нова Кныга, 2006. 512 с.

3. Мангеймський корпус німецької мови (COSMAS) : веб-сайт. URL: http://www.ids-mannheim.de].

4. Медведева Т. С. Этноспецифический концепт Gründlichkeit в немецкой лингвокультуре. Вестник РУДН. Серия Теория языка. Семиотика. Семантика. 2015. Вып. 2. С. 90-99.

5. Остапович О. Я. Корпусний метод у вивченні іноземних мов. Мультимедійна техніка на службі емпіризму. Матеріали Всеукраїнської науково-практичної конференції «Теоретичні та методологічні проблеми дослідження іноземних мов». Київ, 2008. С. 36-40.

6. Приходько А. Н. Концепты и концептосистемы : монография. Днепропетровск : Белая Е. А., 2013.307 с.

7. Uhryniuk R. V. Hauptmerkmale des Konzepts SAUBERKEIT im deutschen Welt-Sprach-Bild. Moderne Germanistik auf der Suche nach einer neuen Identität: Interdisziplinär, Interkulturell, International : Thesenband 27. September - 28. September. Ivano-Frankivsk, 2019. S. 155-156.

\section{REFERENCES}

1. Dronova L. P. Osobennosti kontseptualizatsii predstavleniya o chistote v angliyskom i nemetskom yazykakh [Features of the conceptualization of the notion of purity in English and German]. Tomsk State University Bulletin. 2013. № 368. P. 7-10 [in Russian].

2. Levickij V. V. Semasiologiya [Semasiology] : monograph. Vinnica : Nova Knyga, 2006. 512 p. [in Russian].

3. Manheyms'kyy korpus nimets'koyi movy (COSMAS) [The Mannheim German Reference Corpus (COSMAS)] : website. URL: http://www.ids-mannheim.de] [in German].

4. Medvedeva T. S. Etnospetsificheskiy kontsept Gründlichkeit v nemetskoy lingvokul'ture [Ethno-specific concept of Gründlichkeit in German culture of language]. RUDN Bulletin, series Theory of language. Semiotics. Semantics. 2015 . № 2. P. 90-99 [in Russian].

5. Ostapovych O. Ia. Korpusnyi metod u vyvchenni inozemnykh mov. Multymediina tekhnika na sluzhbi empiryzmu [Corpus method in the study of foreign languages. Multimedia technology in the service of empiricism]. Proceedings of the All-Ukrainian scientific-practical conference "Theoretical and methodological problems of research of foreign languages". Kyiv, 2008. P. 36-40 [in Ukrainian].

6. Prihod'ko A. N. Koncepty i konceptosistemy [Concepts and concept systems] : monograph. Dnepropetrovsk : Belaya E. A., 2013. 307 p. [in Russian].

7. Uhryniuk R. V. Hauptmerkmale des Konzepts SAUBERKEIT im deutschen Welt-Sprach-Bild. Moderne Germanistik auf der Suche nach einer neuen Identität: Interdisziplinär, Interkulturell, International : Thesenband 27. September - 28. September. Ivano-Frankivsk, 2019. S. 155-156 [in German]. 